\title{
Osteoporosis in a cohort of 1062 postmenopausal women
}

Authors: A. Bouzid, D. Meskine, N.Fafa

Laboratoire d'Endocrinologie et Métabolisme (LEM) Alger-1, Alger, ALGÉRIE

\section{Objectives:}

Methods:

Osteoporosis is a disease of the skeletal system characterized by low bone mass and deterioration of bone tissue. it is a worldwide public health problem, particularly in ageing subjects. It is more common in postmenopausal women.

There is lack of information about the risk factor of osteoporosis in developing countries.

The objectives of this study were to screen a sample of postmenopausal women aged $>45$ years for osteoporosis and to identify its risk factors.
This cross-sectional survey was conducted at the endocrinology department of the Bologhine hospital in Algiers, Algeria. A total of 1062 postmenopausal women participated in this study. Each subject completed a questionnaire designed to identify the different etiologies and to document putative risk factors of osteoporosis. The questionnaire covered the following factors and information:

- Demographic characteristics including age, education, occupation, marital status

- Menstrual and obstetrical history: menarche age, age of menopause, parity

- Habits: alcohol consumption, smoking, tobacco use, misheri

- Anthropometric characters: height, weight, BMI.

Calcium intake was evaluated using self-report by Fardellone frequency questionnaire. Bone mineral density was measured on 3 sites (lumbar spine, femoral neck and total hip). Patients were classified as osteopenic, osteoporotic or normal according to WHO diagnosis criteria.
Characteristics of participants $(\mathrm{n}=1062)$

\begin{tabular}{|l|c|}
\hline Variables & \\
\hline Age( year) Mean(SD) & $61,11 \pm 8.49$ \\
\hline Age of puberty(year) Mean(SD & $13.48 \pm 1.64$ \\
\hline Parity & $5.20 \pm 3.68$ \\
\hline History of fractures \% & $26.5 \%$ \\
\hline Weight(kg) & $73.07 \pm 13.34$ \\
\hline Height(cm) & $157.22 \pm 5.98$ \\
\hline BMI(kg/m²) & $29.53 \pm 5$ \\
\hline
\end{tabular}

Adjusted ORs and $95 \%$ CIs of factors statistically associated with osteoporosis in menopausal women

\begin{tabular}{|l|c|c|c|}
\hline Factors & OR ajusted & IC 95\% & P value \\
\hline Age & 1.06 & $1.03-1.0$ & $<0.001$ \\
\hline Age of puberty & 1.13 & $1.03-1.2$ & 0.014 \\
\hline Parity & 1.08 & $1.03-1.1$ & $<0.001$ \\
\hline History of fractures & 1.77 & $(1.24-2.5)$ & 0.002 \\
\hline Weight & 0.91 & $(0.9-0.93)$ & $<0.001$ \\
\hline
\end{tabular}

prevalence of osteoporosis according to the NHANES and OFELY reference curves

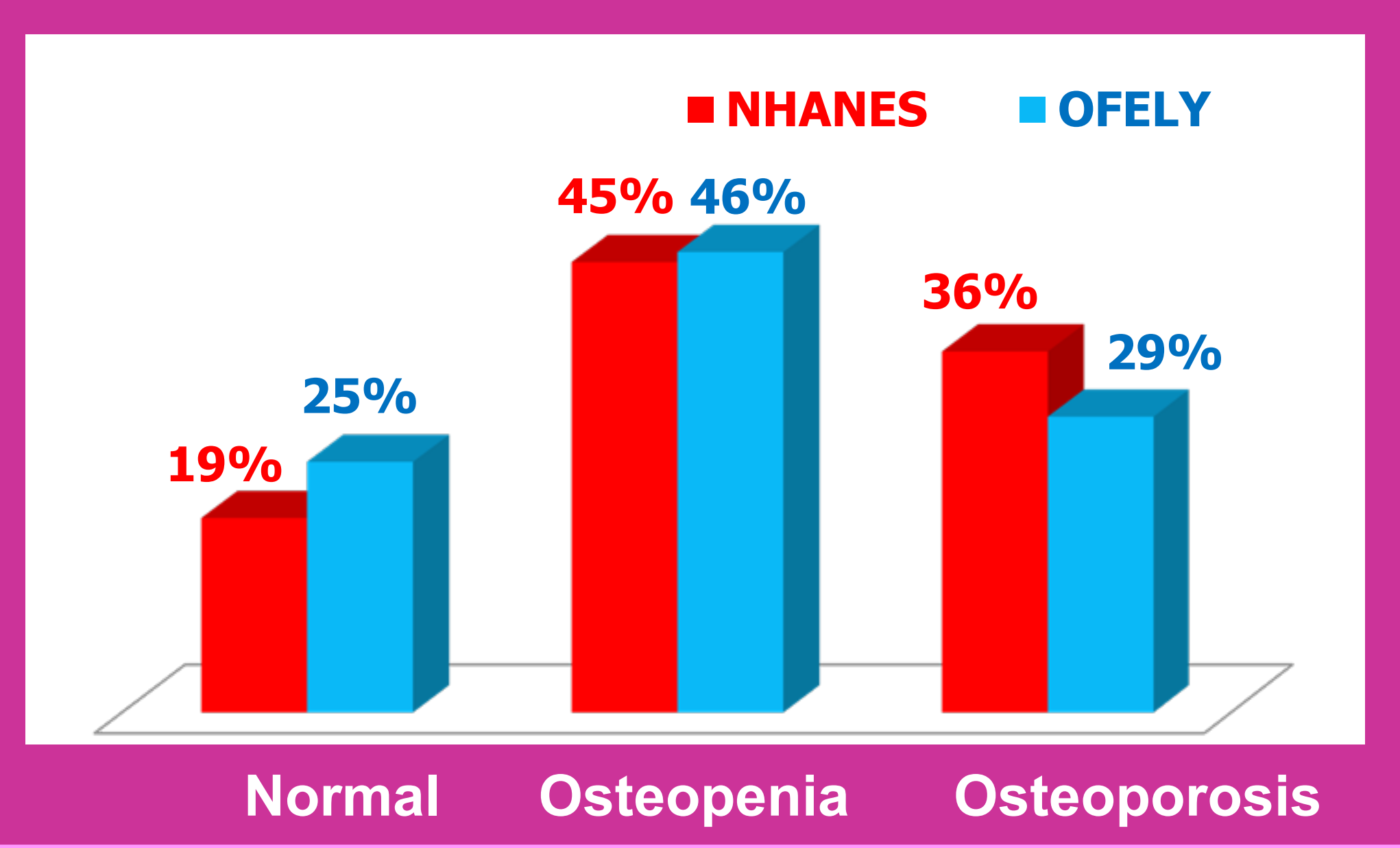

\section{Results:}

The prevalence of osteoporosis according to the NHANES and OFELY reference curves were 35.9\% and 29.4\%, respectively.

Among the evaluated risk factors, age, puberty, parity, weight and personal history of fracture were found to be major determinants of low BMD. Mean age of women was $61.11 \pm 8.49$ years. Mean BMI and weights were $29.53 \pm 5 \mathrm{~kg} / \mathrm{m}^{2}$ and $73.07 \pm 13.34 \mathrm{~kg}$, respectively. Mean age of puberty was $13.48 \pm 1.64$ years and the mean number of pregnancies was $5.20 \pm 3.68$. A history of fracture was noted in 281 patients

\section{Conclusions:}

\section{References:}

The prevalence of osteoporosis was respectively estimated at 35 and 29.4\% according to NHANES and OFELY curves. We found that osteoporosis was frequent in our sample, and was mainly associated with age, puberty, parity, weight and personal history of fracture. Those potential risk factors were validated in epidemiological cohorts.
Osteoporosis, prevention diagnosis and therapy JAMA 2001; 285: 785-795 2) JA Kanis. Diagnosis of osteoporosis and 359:1929-1936 3) Looker A, Orwoll E, Johnston C, Lindsay R, Wahner H, Dunn W, et al. Prevalence of low femoral bone density in older U.S. adults from NHANES III. Journal of Bone Mineral Research. 1997; 12(11) 